\section{Commentary: Bridging the arch in Loey-Dietz syndrome}

\author{
Abe DeAnda, Jr, MD
}

There was a time when a young (and sometimes not so young) patient with an aortic dissection or root aneurysm was suspected as having Marfan syndrome (MFS), even when clinical evidence suggested otherwise. With the identification a mutation on the $F B N 1$ gene $^{1}$ as the culprit in MFS, patients with aortic disease and evidence of a connective tissue disorder were sometimes lumped in the same category; that is, automatically classified as having MFS. In some cases, when MFS was conclusively demonstrated not to be the causative factor, a patient was simply labeled marfanoid. The most recent iteration of the Ghent nosology recognizes the subset of patients with sufficient criteria for MFS but with unexpected findings. ${ }^{2}$ The more recognizable of these alternative diseases that share characteristics with MFS include Loey-Dietz syndrome (LDS) and Sphrintzen-Goldberg syndrome, but others exist. In a recent review, 37 distinct genes with genetic variants or mutations associated with thoracic aorta aneurysmal disease were identified, ${ }^{3}$ but there are more genes that are yet to be discovered, ${ }^{4}$ and distinct phenotypes can be seen with each variant.

The benefit of knowing the causative syndrome is that clinical management and surgical timing can be optimized. Knowing how each of these connective tissue disorders behaves compared with nongenetic causes can alter our medical and surgical management of these diseases. For example, LDS was recognized (incorrectly because the genes involved are different) early on as a more aggressive form of MFS; thus, was intervened on earlier to avoid a downstream catastrophic aortic event.

Schoenhoff and colleagues ${ }^{5}$ leverage the experience and volume of Johns Hopkins Medical Institutions to ask how

\footnotetext{
From the Division of Cardiovascular and Thoracic Surgery, University Texas Medical Branch-Galveston, Galveston, Tex.

Disclosures: The author reported no conflicts of interest.

The Journal policy requires editors and reviewers to disclose conflicts of interest and to decline handling or reviewing manuscripts for which they may have a conflict of interest. The editors and reviewers of this article have no conflicts of interest

Received for publication July 16, 2020; revisions received July 16, 2020; accepted for publication July 17, 2020; available ahead of print July 19, 2020.

Address for reprints: Abe DeAnda, Jr, MD, Division of Cardiovascular and Thoracic Surgery, University Texas Medical Branch-Galveston, 301 University Blvd, Galveston, TX 77551 (E-mail: abdeanda@utmb.edu).

J Thorac Cardiovasc Surg 2020;160:1176-7

$0022-5223 / \$ 36.00$

Copyright (c) 2020 by The American Association for Thoracic Surgery

https://doi.org/10.1016/j.jtcvs.2020.07.057
}

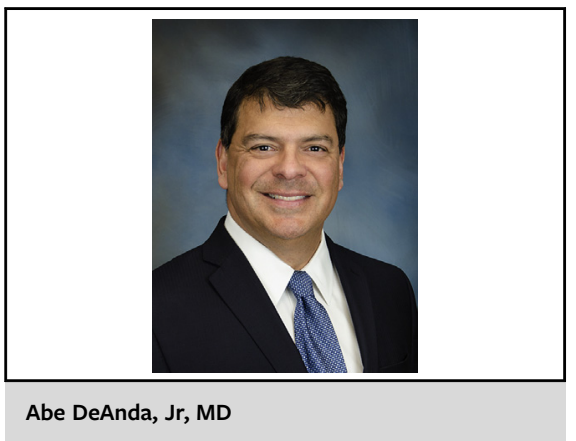

CENTRAL MESSAGE

Interventions of the proximal aorta in Loey-Dietz syndrome may result in the need for secondary interventions on the arch, with a mortality risk. A teardirected approach may lower this risk.

the aortic arch should be managed at the time of proximal aortic surgery, comparing patients with MFS and those with LDS. These groups did not have the same baseline characteristics, LDS patients were younger, and they underwent intervention at smaller aortic diameters. When separated out by the presence or absence of acute aortic dissection (AAD), for the patients without dissection there was a significant increase in the need for subsequent arch surgery in the LDS patients with an associated increase in the risk for late mortality. With AAD, the incidence of secondary arch intervention was statistically the same between LDS and MFS patients.

There are 2 subtle but potentially important findings within the data outside of the recommendations and conclusions of the authors. First, although the incidence of secondary arch intervention was the same for both LDS and MFS patients when AAD occurs, it should be noted that 7 of 12 patients in the LDS with AAD group had either primary or secondary arch interventions, whereas 24 of 26 patients in the MFS with AAD group required intervention. Perhaps the take-home message here is that MFS patients should have their arch addressed more aggressively at the first operation.

Second, for patients without AAD, LDS patients had a higher incidence for needed arch replacement $(5 \%$ vs $0.4 \%)$ as well as subsequent aortic surgery $(12 \%$ vs $1.3 \%$ ). I propose that the reason might rest in a combination of surgical technique and a difference in mechanical 
characteristics of the aorta in LDS versus MFS patients. In the setting of AAD, it is the practice at Johns Hopkins to perform the distal anastomosis open, presumably regardless of the patient's genotype. Likewise, unless the arch is enlarged, it is their practice to clamp the aorta just proximal to the innominate artery. Atraumatic clamps are not atraumatic, and injury to the media and/or intima with clamping may lead to downstream effects. If the tissue of Loey-Dietz is more vulnerable to crush injury it would stand to reason that subsequent pathology could follow.

The tear-directed and pathology-oriented approach by the team at Johns Hopkins continues to lead the way in the diagnosis and management of connective tissue disorders. This latest study adds to our understanding of the subtle differences in these potentially deadly diseases.

\section{References}

1. Dietz HC, Cutting GR, Pyeritz RE, Maslen CL, Sakai LY, Corson GM, et al. Marfan syndrome caused by a recurrent de novo missense mutation in the fibrillin gene. Nature. 1991;352:337-9.

2. Loeys BL, Dietz HC, Braverman AC, Callewaert BL, De Backer J, Devereux RB, et al The revised Ghent nosology for the Marfan syndrome. J Med Genet. 2010;47:476-85.

3. Vinholo TF, Brownstein AJ, Ziganshin BA, Zafar MA, Kuivaniemi H, Body SC, et al. Genes associated with thoracic aortic aneurysm and dissection: 2019 update and clinical implications. Aorta (Stamford). 2019;7:99-107.

4. Pinard A, Jones GT, Milewicz DM. Genetics of thoracic and abdominal aortic diseases. Circ Res. 2019;124:588-606.

5. Schoenhoff FS, Alejo DE, Black JH, Crawford TC, Dietz HC, Grimm JC, et al Management of the aortic arch in patients with Loey-Dietz Syndrome. J Thorac Cardiovasc Surg. 2020;160:1166-75.
See Article page 1166.

\section{Commentary: Aortic surgery in patients with Loeys-Dietz syndrome: When, why, and how?}

\author{
Severino Iesu, MD, ${ }^{\mathrm{a}}$ Pierpaolo Chivasso, $\mathrm{MD},{ }^{\mathrm{a}}$ and \\ Vito Domenico Bruno, $\mathrm{MD}, \mathrm{PhD}^{\mathrm{b}}$
}

Connective tissue disease (CTD) represents a rare genetic disorder that determines the weakness of the blood vessels and can lead to severe complications such as aneurysms, aortic dissections, and vascular ruptures. The most common disorders are Marfan syndrome (MFS) and Loeys-Dietz syndrome (LDS): These clinical entities are caused by mutations in the genes encoding fibrillin-1 and transforming growth factor- $\beta$ receptors 1 and 2 , SMAD3, or transforming growth factor-B2, respectively. ${ }^{1}$ Aortic dissections and

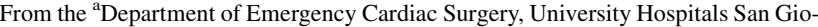
vanni di Dio e Ruggi d'Aragona, Salerno, Italy; and 'Bristol Medical School, Translational Health Science Department, Bristol, United Kingdom.

Disclosures: The authors reported no conflicts of interest.

The Journal policy requires editors and reviewers to disclose conflicts of interest and to decline handling or reviewing manuscripts for which they may have a conflict of interest. The editors and reviewers of this article have no conflicts of interest.

Received for publication July 17, 2020; revisions received July 17, 2020; accepted for publication July 20, 2020; available ahead of print July 22, 2020.

Address for reprints: Vito Domenico Bruno, MD, PhD, Translational Health Science Department, Bristol Medical School, University of Bristol, Research Floor Level 7, Bristol Royal Infirmary, Upper Maudlin St, BS2 8HW Bristol, United Kingdom (E-mail: Vito.D.Bruno@bristol.ac.uk).

J Thorac Cardiovasc Surg 2020;160:1177-8

0022-5223/\$36.00

Copyright (c) 2020 by The American Association for Thoracic Surgery

https://doi.org/10.1016/j.jtcvs.2020.07.061
}

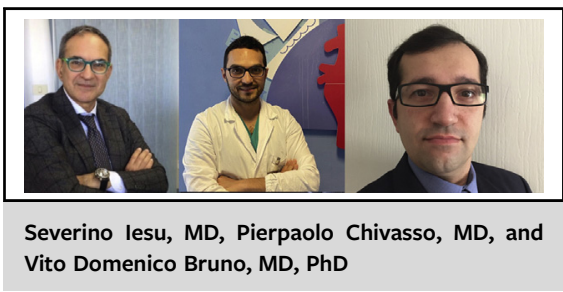

CENTRAL MESSAGE

Loeys-Dietz syndrome is rare but can lead to severe complications of the aorta. Knowing what to do in the presence of a patient with this disease is important for any aortic surgeon.

aneurysms are leading factors affecting morbidity and mortality in this cohort of patients, and the surgical treatment of CTD-related thoracoabdominal aortic aneurysm still represents a challenge. Current guidelines for the repair of root and ascending aortic disease are well established, and several prior studies have reported good outcomes after elective surgery in this subset of patients. ${ }^{2}$ Modern molecular biology advancements, such as mapping of the human genome and the refinement of surgical techniques, have significantly improved the management and life expectancy 